\title{
Porcos da metrópole e atuns da colônia: adaptação alimentar dos colonizadores europeus na América portuguesa quinhentista
}

Cerdos de la metrópoli y atunes de la colonia: adaptación alimentaria de los colonizadores europeos en la América portuguesa quinientista Pigs of the Metropolis and Tunas of the Colony:
Nutritional adaptation in sixteenth-century
Portuguese America

Christian Fausto Moraes dos Santos* Gisele Cristina da Conceição** Fabiano Bracht***

Resumo: A partir de cartas, tratados e relatos produzidos na América portuguesa do século XVI, analisamos alguns traços do cotidiano nutricional vivido pelos europeus que se estabeleceram no litoral. Para tal, abordamos questões estratégicas como o desenvolvimento das técnicas de cultivo, coleta e pesca, bem como a introdução, adaptação e aclimatação de algumas espécies animais e vegetais, oriundos da Europa. A partir da perspectiva da História das Ciências, buscamos compreender como o novo Mundo Natural encontrado pelos europeus ao desembarcarem

* É pós-doutor em História Social da Cultura pela UFMG e doutor em História das Ciências e da Saúde pela Fundação Oswaldo Cruz. Atualmente é professor não titular da Universidade Estadual de Maringá e coordenador do Laboratório de História, Ciências e Ambiente.<chrfausto@gmail.com>.

* Doutoranda em História pela Universidade do Porto, com bolsa do Programa de Doutorado Pleno no Exterior da Capes. Mestre em História pela Universidade Estadual de Maringá. É graduada em História pela mesma instituição (UEM). Membro pesquisadora do Laboratório de Pesquisado em História, Ciências e Ambiente (LHC). <giselecconceicao@gmail.com>.

*** Doutorando em História pela Universidade do Porto, com bolsa do Programa de Doutorado Pleno no Exterior da Capes. Mestre em História pela Universidade Estadual de Maringá. Possui graduação em História pela mesma instituição. Membro pesquisador do Laboratório de História Ciências e Ambiente (LHC). <fabianobracht@yahoo.com.br>. 
nos trópicos, contribuiu não somente à sobrevivência destes, como também, na construção de novos paradigmas no campo da Filosofia Natural.

Palavras-chave: História das Ciências. América portuguesa. Adaptação alimentar. Colonização.

Resumen: A partir de cartas, tratados y relatos producidos en la América portuguesa del siglo XVI, analizamos rasgos nutricionales del cotidiano vivido por los europeos que se establecieron en el litoral. Para tanto, estudiamos cuestiones estratégicas como el desarrollo de las técnicas de cultivo, colecta y pesca, así como la introducción, adaptación y aclimatación de algunas especies de animales y vegetales, venidos de Europa. A partir de la perspectiva de la Historia de las Ciencias, hemos buscado comprender como el nuevo mundo natural encontrado por los europeos, cuando llegaron en los trópicos, ha contribuido no solamente a su supervivencia, como también, en la construcción de nuevos paradigmas en el campo de la Filosofía Natural.

Palabras clave: Historia de las Ciencias. América portuguesa. Adaptación alimentar. Colonización.

\begin{abstract}
From letters, treaties and reports produced in Portuguese America from the sixteenth-century, we analyze some of the daily nutritional traits experienced by Europeans who settled on the coast. To this end, we address strategic issues such as the development of farming techniques, gathering and fishing, as well as the introduction, adaptation and acclimatization of some animal and plant species, from Europe. From the perspective of the history of science, we seek to understand how the new Natural World encountered by Europeans on their arrival in the tropics, not only contributed to the survival of these, as well as in the construction of new paradigms in the field of Natural Philosophy.
\end{abstract}

Keywords: History of Science. American Portuguese. Feeding adaptation. Colonization.

\title{
Introdução
}

Os primeiros colonizadores lusos que desembarcaram no Novo Mundo se depararam com uma fauna e flora que, a partir de sua perspectiva, eram totalmente novas. Tal diversidade e estranhamento ecológico implicaram, ainda, nas dificuldades em se adaptar às condições dos domínios morfoclimáticos tropicais. Fatores que, certamente, exerceram alguma influência no processo de colonização promovido pelos europeus, bem como dos animais e plantas domésticos que desembarcavam das naus que aportavam no Novo Mundo. Tais questões ambientais e biogeográficas se revelaram um obstáculo complexo, sobretudo, nos primeiros decênios do processo colonizatório da América portuguesa.

Mesmo com a grande diversidade de animais e plantas disponíveis, a obtenção de alimentos, certamente, despendia um gasto calórico 
considerável, uma vez que os conhecimentos técnicos sobre caça e pesca, detido pelos colonizadores não se aplicavam, de imediato, ao processamento e consumo dos seres daquele ecossistema.

É provável que uma das primeiras dificuldades com que os europeus se defrontaram, quando aportaram nas terras do Novo Mundo, foi a de encontrar fontes de proteínas e gordura animal necessários à sua subsistência. Obter alimentos, de qualquer gênero, apresentou-se enquanto uma tarefa complexa. Mesmo que as reservas proteicas existentes na América fossem diversas, os europeus precisavam se adaptar a novos métodos de obtenção de alimentos que encontrassem no ecossistema da América quinhentista. Manter, na colônia, uma reserva de víveres trazidos da Europa, do ponto de vista logístico, não era tarefa fácil. Havia uma gama de obstáculos impedindo que este translado fosse efetuado com frequência, uma vez que o custo das viagens ultramarinas eram elevados e as condições necessárias para transportar animais vivos, ou processados na forma de alimentos, era complexa. Soma-se a isso, o fato de que o clima quente e úmido dos trópicos dificultava, e muito, a conservação de alguns alimentos trazidos da Europa. As técnicas conhecidas na Europa, para a conservação de víveres, como o presunto ibérico, não se encaixavam naquele ambiente, o que tornava o mantenimento alimentício ainda mais complexo e trabalhoso.

Diante do exposto, pretendemos analisar neste artigo, os processos de adaptações dos primeiros colonizadores portugueses na América no século XVI, principalmente relacionados aos alimentos. A partir dos paradigmas teóricos e metodológicos da História das Ciências e a interdisciplinaridade com outras áreas de pesquisa, como a zoologia e a nutrição, buscamos compreender como se deu tal processo de adaptação, analisando fontes documentais a muito conhecidas pela historiografia, como o Tratado Descritivo do Brasil de Gabriel Soares de Sousa (1587). Observamos as descrições e classificações de animais encontrados ao longo da costa americana e que foram incorporados ao cotidiano alimentar dos portugueses que se fixaram nos trópicos.

\section{Novo ecossistema, nova alimentação.}

Alguns fatores morfoclimáticos foram relevantes no processo de deslocamento dos colonizadores europeus durante a Modernidade. Afinal, quando as naus portuguesas aportaram nas costas da América, estas não cruzaram somente o Atlântico no sentido Leste-Oeste, mas 
também no sentido Norte-Sul. Tal informação, obviamente, não nos aponta somente o rumo seguido pelas embarcações lusas. Enquanto se deslocavam nesta direção, os colonizadores cruzavam vários paralelos, o que proporcionou a passagem por diferentes regimes de insolação, biomas e uma variedade considerável de características físicas. À medida que os portugueses promoviam sua expansão marítima, sobretudo em direção à África e América portuguesa, estes se deslocavam em um sentido longitudinal. O que nos remete ao fato dos colonizadores terem encontrado uma ampla diversidade climática e biogeográfica, que em muito influencia ciclos de plantio, colheita, criação de plantas e animais domésticos (Diamond, 2008).

Para o historiador das ciências Jared Diamond, o fenômeno da domesticação de animais e plantas é primordial para compreendermos processos civilizacionais. Ela, a domesticação, teria significado muito mais do que comida e populações humanas mais numerosas, influenciando no desenvolvimento das sociedades e nas suas formas de organização. Esse fenômeno demonstra que regimes alimentares tem um papel considerável na história de civilizações. O que tornou os primeiros grupamentos humanos capazes de cultivar e processar seus próprios alimentos foi resultado de um complexo processo de superação e domesticação de alguns elementos da natureza (Diamond, 2008). O que nos leva a refletir que a busca diária por comida, em partes, foi revivida por aqueles primeiros homens da era moderna que se lançaram à colonização do Novo Mundo no século XVI. Afinal, muito teve de ser repensado em termos da domesticação de espécies endêmicas e introdução de exóticas.

Seria anacrônico pensarmos que fatores desta ordem não foram relevantes no processo de colonização da América portuguesa, ou que a introdução da fauna e flora doméstica trazida da Europa se deu sem qualquer percalço. Para animais e plantas, domesticados ou não, colonizar um novo ambiente não é apenas uma questão de chegar lá (Quammen, 2008). A dispersão é apenas a primeira etapa deste processo, nela a planta ou animal em questão tem de se aclimatar a novos regimes de insolação, umidade e pressão do ar, além de fatores físicos e químicos do solo e água. A segunda etapa envolve aquilo que os ecólogos chamam de estabelecimento (Odum, 2004). Tão ou mais complexo que a dispersão, o estabelecimento envolve os obstáculos referentes à fixação de uma população autossustentável (Quammen, 2008, p. 157). Obter alimento e se adaptar ao estresse causado por novos predadores são algumas das variáveis na equação da introdução 
de espécies exóticas em um ambiente, principalmente um rico em biodiversidade como o da mata atlântica brasileira.

Tais características demonstram que questões de ordem física, fossem elas geológicas, bióticas ou climáticas, também podem ser considerados como fatores de primeira ordem no estudo da trajetória colonizadora dos europeus ibéricos nos trópicos. Esses problemas ficam evidentes quando observamos a descrição de Gabriel Soares de Sousa referente à introdução de hortaliças do Velho Mundo na América portuguesa, tais como Salsa (Petroseluim sativum) e Couve (Brassica oleracea):

As couves tronchudas e murcianas se dão tão boas como em Alvalade, mas não dão semente [...] a salsa se dá muito formosa, e se no verão tem conta com ela, deitando-lhe em pouca de água, nunca se seca, mas não dá semente nem espiga (Sousa, 1971, p. 170).

Hoje sabemos que fatores climáticos e agentes polinizadores são agentes diretos nos processos de germinação, crescimento e resistência à doença das plantas. No caso da Salsa e da Couve, relatadas por Gabriel Soares, a ausência de produção de sementes poderia, obviamente, se revelar um problema na medida em que a cada novo plantio mais remessas de sementes deveriam ser trazidas da Europa. Não podemos esquecer o fato de que o translado entre o velho e o novo continente era relativamente demorado, e que os custos deste processo eram consideravelmente elevados.

Assim como, muitas vezes, não havia um predador natural coevoluído que ameaçasse algumas espécies introduzidas (o que lhes garantia uma adaptação formidável), em outros casos faltavam agentes de polinização especializados para ajudar a promover a propagação sexuada, ou seja, pelos grãos, como no caso das salsas. Cada espécie de planta encontrava obstáculos particulares em seu processo de adaptação. O desenvolvimento de germinação, crescimento e resistência à doença, no caso das plantas molda-se, a princípio, por características específicas do clima. Tal dinâmica é estabelecida a partir de um programa genético regido por mecanismos da seleção natural. A planta em questão reage aos sinais da natureza de acordo com o regime sazonal no qual se desenvolveu. Dessa forma, a duração do dia, a chuva e temperatura formam predomínios variantes para a planta da mesma forma que as suas adaptações para doenças são predominantes da latitude onde crescem (Diamond, 2008, p. 114-129). Se os colonizadores chegavam 
à colônia trazendo seus hábitos, valores, enfim, sua cultura, as plantas e animais que os acompanhavam, de certa forma, também desembarcavam com suas preferências e critérios ambientais.

Para além deste agravante logístico ambiental, devemos nos lembrar de que esta aparente esterilidade botânica relatada pelo senhor de engenho Gabriel Soares de Sousa está diretamente relacionada a mecanismos naturais construídos ao longo de milhares de anos de seleção natural, na medida em que os seres vivos evoluem reagindo aos sinais da natureza em resposta às particularidades do regime sazonal no qual se desenvolveram. A duração do dia, a chuva, estações do ano e temperatura formam condicionantes que se exprimem na evolução da planta, da mesma forma que as suas adaptações defensivas são adequadas para combaterem as doenças e parasitos relativos à latitude onde se especiaram (Diamond, 2008).

O problema encarado pelas hortaliças plantadas por Sousa, provavelmente, estava relacionado à inversão das estações do ano enfrentadas pelas mesmas no processo de germinação no Novo Mundo, bem como um aumento considerável do nível de insolação. Um obstáculo que poderia até ser superado pela própria planta, mas que poderia levar algum tempo até que esta evoluísse, metabolicamente, às novas condições climáticas. A questão dos agentes polinizadores também é importante. Um dos principais insetos responsáveis pela polinização de plantas nativas da região mediterrânica central e costa ocidental europeia como a salsa (Petroselinum crispum) e a couve (Brassica oleracea), é uma abelha que co-evoluiu com a mesma no continente europeu. Estamos nos referindo a abelha europeia (Apis mellifera). Inseto que só foi introduzido no Brasil no século XIX (Delariva; Agostinho, 1999, p. 255-262).

Os processos de introdução de animais domésticos, oriundos do Velho Mundo, seguiram parâmetros muito semelhantes. Lembremonos que a introdução destes animais foi um processo que demandou considerável tempo. Não somente por conta das espécies predadoras encontradas na América portuguesa, entre elas morcegos hematófagos, grandes felinos e ectoparasitos hematófagos como percevejos, pulgas (Pulicidae), carrapatos (Ixodidae Argasidae) e bichos de pé (Tunga penetrans) como na própria adaptação dos animais domésticos trazidos da Europa (Santos et al., 2007, p. 561-573; Crosby, 2011). É importante nos atentarmos para o fator, por vezes limitador, presente na diversidade geográfica e climática, uma vez que no Brasil observamos, ao menos, sete diferentes domínios morfoclimáticos. Ou seja, a cada 
domínio os animais introduzidos pelo colonizador, durante o processo de expansão, tinham sua resiliência testada, seja por fatores ligados às novas condições climáticas, ou pela mudança na dieta alimentar ${ }^{1}$ (Reitz, 1992, p. 84-91). O que, não raramente, implicava em um possível retardo da proliferação e mantenimento de uma fonte de proteína que, em teoria, deveria estar sempre à disposição. Neste último caso, podemos elencar o porco doméstico europeu (Sus scrofa domesticus) que, apesar de ser uma considerável fonte de proteína e gordura, não possuía um sistema homeostático tão bem adaptado à regiões com alto grau de insolação (Crosby, 2011).

A introdução e aclimatação de animais euroasiáticos tais como galinhas (Gallus gallus), porcos (Sus scrofa), ovelhas (Ovis aries), cabras (Capra Aegagrus hircus) e gado bovino (Bos taurus), levou certo tempo para se consolidar e oferecer um suprimento regular de proteína e gordura. Provavelmente, somente nos últimos decênios do século XVI, a América portuguesa contava com um rebanho de animais de corte abundante o suficiente para suprir a demanda da colonização. De todas as crônicas, cartas e tratados escritos no século XVI, somente Gabriel Soares de Sousa, em 1587, faz o primeiro relato de porcos domésticos de origem europeia apresentando a resiliência típica da espécie:

A porca pare infinidade de leitões, os quais são muito tenros e saborosos, e como a leitoa é de quatro meses espera o macho, pelo que multiplicam coisa de espanto, porque ordinariamente andam prenhes, de feição que parem três vezes por ano, se lhe não falta o macho (Sousa, 1971, p. 165).

Além de Gabriel Soares, somente o padre Fernão Cardim, em 1590, observou que os porcos começavam a se tornar mais frequentes nas vilas e arraiais da América portuguesa. O jesuíta português também nos indica que a maior incidência destes animais, nas terras da colônia, era algo relativamente recente. Segundo suas observações "os porcos se dão cá bem, e começa de haver grande abundância [...] (Cardim, 1980, p. 66, grifo nosso)".

Problemas relacionados com a adaptação de animais europeus introduzidos nas colônias americanas ao longo de século XVI não são privilégios apenas dos colonizadores portugueses. Elizabeth J. Reitz, pesquisadora do Museu de História Natural da Geórgia, constatou que os colonizadores espanhóis também enfrentaram obstáculos quando da transposição de espécies de animais europeus para suas colônias no Novo Mundo. Para a pesquisadora, os fatores climáticos, assim como a alimentação, têm de ser considerados quando analisamos os processos de colonização, no caso, dos espanhóis (Reitz, 1992). 
Das raças suínas nativas de Portugal, a que mais se destacou foi a do porco alentejano. Sua origem ibérica remonta aos primeiros javalis do sul (Sus mediterraneus) que foram domesticados naquela região da Europa. O porco alentejano era, provavelmente, o candidato mais apto a embarcar com os colonizadores portugueses nas naus que zarpavam da ribeira em Lisboa. Provavelmente, a principal qualidade do porco alentejano consistia em sua grande capacidade adipogênica, ou seja, aquilo que os zootecnistas hoje chamam de porco de banha. Suas carnes e toucinhos eram próprias para a produção de banha, toucinhos, linguiças e curados como o presunto ibérico (Ferreira, 2005).

Mesmo sendo habituado a um clima mais quente que outra raça tradicional de suínos portugueses, a do porco celta, desenvolvido a partir do javali (Sus scrofa ferus), o porco alentejano deve ter passado por alguns percalços ao ser introduzido em um ambiente consideravelmente mais quente e úmido que o ameno mediterrâneo. Outro obstáculo à introdução do alentejano, na América portuguesa, estava relacionado a um importante aspecto cultural da criação destes animais na península ibérica. Tradicionalmente, esta raça de porcos era criada em um sistema de produção comum nas regiões sul de Portugal e Espanha, tratava-se da utilização de um ecossistema conhecido como montado. Nele, os porcos ficavam soltos em extensas pastagens, onde se alimentavam dos frutos de carvalhos (Quercus ilex e Quercus suber) (Mariante; Cavalcante, 2006, p. 204).

Curiosamente, até a década de 1990, os porcos alentejanos eram criados, em Portugal, neste tradicional sistema de manejo extensivo (Silva, 2008, p. 06). O que nos leva a refletir, o quanto pode ter sido atribulada a introdução, dispersão e adaptação deste estratégico animal doméstico durante os primeiros decênios da colonização. Pensemos nas inúmeras porcas prenhes que morreram de sepse ou raiva após as visitas seguidas de algum morcego hematófago (Desmodus rotundus), quantos porcos soltos nunca mais foram vistos ao se tentar reproduzir, nos trópicos, o regime de criação adotado nos montados alentejanos (Santos et al., 2007). Os motivos para o criador de porcos da colônia nunca mais ver seus animais poderiam ainda incluir a predação de grandes felinos como a onça (Panthera onca) e a suçuarana (Felis concolor). Mesmo a pequena jaguatirica (Leopardus pardalis), não teria muita dificuldade em abater e arrastar para a mata um jovem bacorinho. Como já afirmamos, poderíamos incluir também parasitos como pulgas (Tunga gracilis) e carrapatos (Amblioma sp.) além das inúmeras miíases como bernes (Dermatobia hominis) e moscas varejeiras (Calliphoridae, 
Oestridae, Sarcophagidae) que não se demorariam em depositarem seus ovos e larvas em alguma lesão cutânea oriunda do esbarrão em um tucum (Bactris sp.), uma palmeira nativa da mata atlântica conhecida pelos seus grandes espinhos.

As questões que envolveram a introdução do porco doméstico podem contribuir com importantes indícios à compreensão das dificuldades em se implantar, nos trópicos, alguns aspectos do modo de vida europeu. Importante fonte de alimento para as comunidades europeias no século XVI, os porcos eram constantemente arregimentados para seguirem nas expedições portuguesas (Mariante, Cavalcante, 2006). Generalistas pouco exigentes com relação à alimentação e oportunistas natos, os porcos desempenharam papel relevante na Europa, contribuindo substancialmente para o desenvolvimento do regime agrícola naquele continente (Dean, 2010). O porco servia como fonte de alimento que podia ser armazenada por um período de tempo considerável, principalmente depois de abatido, quando podia ser utilizado na produção de inúmeras iguarias como presuntos defumados, linguiças e toucinho. Este último, por conta de ser, ao mesmo tempo, uma estratégica fonte de proteína e gordura, teve uma importância considerável no cotidiano alimentar durante todo o período colonial (Santos et al., 2010, p. 273-286).

Quando analisamos os métodos europeus de conserva tradicionais, como o do presunto ibérico, temperado com pouco sal e curado ao natural, concluímos que nas primeiras vezes em que os mesmos foram empregados estes devem ter se tornado, na América tropical, um meio de cultura para larvas das inúmeras espécies de dípteras, principalmente as do Gênero Cochliomya, uma vez que o tempo entre o início do processo de cura e salga do presunto até o produto final, pode variar de um a dois $\operatorname{anos}^{2,3}$ (Case, 2009, p. 578). A questão climática também é um fator que, não raramente, faz com que técnicas de conservação tenham de ser

2 Segundo Francis Case, “[...] Os presuntos serranos primeiro são salgados por cerca de duas semanas para se extrair o excesso de umidade. Depois são lavados e pendurados para secar. Por fim, são curados ao ar, geralmente de um a dois anos, período em que podem perder até $50 \%$ do peso. Não são defumados durante o processo de cura [...]" (Case, 2009, 578).

3 Um estudo recente, realizado por pesquisadores da área de engenharia e tecnologia de alimentos, demonstram processos de aceleramento no tempo de cura e salga de diversos tipos de presuntos defumados, inclusive o presunto ibérico. Nos processos atuais de preparo deste alimento, o tempo foi reduzido em até 5 meses (Bergamin Filho et al., 2010), o que é de fato interessante, pois, mesmo em processos atuais de cura e salga, o tempo estimado para se obter o produto final ainda é relativamente longo. 
constantemente repensadas. Quando comparamos a temperatura média anual de Portugal com a da Bahia, por exemplo, a diferença entre ambos é de, praticamente, o dobro. Enquanto o clima mediterrâneo português propicia médias anuais de $14^{\circ} \mathrm{C}$ (Magnoli, 2005, p. 80-97), a quente e úmida Bahia pode apresentar médias anuais de $27^{\circ} \mathrm{C}$ (Magnoli, 2005, p. 99-118). O mesmo valendo para os índices pluviométricos.

Tais números podem ser impactantes quando se coloca um pernil de porco para curar atrás da porta de casa. $\mathrm{O}$ teor de água (umidade interna e externa) da carne de porco, por exemplo, é de aproximadamente $60 \%$. Para os engenheiros de alimentos é considerado um teor alto, o que permitiria uma rápida colonização por bactérias e bolores. Boa parte de um processo de cura eficiente consiste em se drenar este teor de água existente na carne a ser conservada, o que pode ser dificultado pela perigosa combinação de alta umidade relativa do ar e temperaturas elevadas. Não é difícil presumirmos que a temperatura média, em um dia de verão na capitania da Bahia pudesse chegar aos $37^{\circ} \mathrm{C}$. Nesta temperatura, algumas bactérias saprófitas podem se multiplicar a taxas assustadoras, chegando a números de 1.000 a 10.000 .000 de organismos individuais em sete horas (Berkel et al., 2005). Números que, certamente, ensinaram aos primeiros colonizadores com quanto sal se fazia uma carne curada na colônia.

Ao que tudo indica, estes fatores ambientais pontuais estabeleceram um interessante diálogo com a cultura e técnicas relacionadas à alimentação dos primeiros europeus que se estabeleceram nas bordas da mata atlântica. Enquanto o manejo do porco criado solto era repensado e a quantidade de punhados de sal a serem esfregados nos pernis e lombos reavaliados, a caça e pesca de animais nativos na colônia deve ter sido, aos olhos do colonizador, tão preciosa quanto às toras de pau-brasil ou pães de açúcar.

Paradoxalmente, parte da solução (e também do problema) passou a ser encontrar alimentos nativos da colônia, principalmente fontes de proteína e gordura animal, de forma eficiente e segura. Neste ponto, a fixação dos colonizadores no litoral pode ser considerada como estratégica à sobrevivência destes, afinal, os animais marinhos possuem alto teor de gordura e proteína, sendo que algumas espécies podem ser pescadas e ou coletadas com certa facilidade, possibilitando um baixo gasto calórico para tanto.

Para o colonizador, encontrar formas de obter alimentos que pudessem suprir, de imediato, sua necessidade mais básica, ou seja, se alimentar dependeu de alguns fatores importantes. Era necessário 
saber por que se deveria tomar cuidado com as ovas da aimoreuçu (Gymnothorax ocellatus), uma moreia que, apesar de ter a carne saborosa, "[...] as ovas são peçonhetas, e de improviso se acha mal quem as come [...]" (Sousa, 1971, p. 187), ou porque as ameijoas de água doce, sempre que possível, eram preteridas às suas equivalentes de água salgada, pois:

Assim como a natureza criou tanta diversidade de mariscos na água salgada, fez o mesmo nos rios e lagoas de água doce, como se verá pelos mexilhões que se criam nas pedras destes rios e no fundo das lagoas, que são da feição e tamanho dos do mar, os quais não são tão gostosos por serem doces (Sousa, 1971, p. 297).

Atos como os de identificar habitats, classificar tamanhos, cores e sabores de peixes, ostras e moluscos como o aimoreuçu ou as ameijoas de água doce, eram essenciais para os primeiros europeus que se fixaram no litoral da América portuguesa. As quase 1000 descrições de animais que encontramos nos relatos, crônicas, cartas e tratados escritos pelos primeiros colonizadores são mera consequência daquilo que era, tanto um empenho, quanto uma necessidade.

Definitivamente, os primeiros colonizadores tinham de dividir a atenção entre o tráfico de pau-brasil e uma apreensão detalhada do meio, afinal, fenômenos como o hábito se alimentar de caranguejos, ou mesmo o ritmo das marés em uma enseada, poderiam significar a diferença entre ter ou não o que comer (Lopes, 2005, p. 457-470).

É a partir desta perspectiva que o relato de Gabriel Soares de Sousa ganha considerável importância, uma vez que o explorador observou o comportamento dos guaiauçá, pequenos caranguejos que "[...] se criam dentro da areia que se descobre na vazante da maré [...] e andam sempre pelas praias, enquanto não vem gente, e como a sentem se metem logo nas covas [...]" (Sousa, 1971, p. 269).

Esta passagem denota, não somente uma intenção pragmática de Gabriel Soares quanto à observação do comportamento daquele animal e do ambiente ao qual ele estava inserido. Podemos observar, também, a percepção do quão relevante era a observação e descrição de animais nativos da América portuguesa, tanto no que se refere à própria alimentação, quanto a construção de conhecimentos acerca de tudo o que norteava o cotidiano daqueles homens. No caso do guaiauçá, hoje popularmente chamado de caranguejo da areia ou maria-farinha (Ocypode albicans), o interesse de Gabriel Soares se deu graças a observação de uma técnica de pesca indígena que utilizava este pequeno 
crustáceo como isca. De fato, a preferencia dos indígenas pelo guaiauçá era tanta que:

[...] aconteceu já fazer um índio tamanha cova, para tirar um destes caranguejos, que lhe caiu areia em cima de maneira que não pode tirar a cabeça e afogou-se; no que os índios tomam tanto trabalho, por que lhes serve este guaiauçá de isca que o peixe come bem [...] (Sousa, 1971, p. 290).

De fato, uma isca que deveria recompensar o esforço.

\section{"O peixe que nasce no mar deve morrer no óleo": Os frutos do mar como parte do cotidiano alimentar.}

Quando o tema era alimentação, não raramente, técnicas indígenas foram adotadas ou adaptadas às necessidades fisiológicas e culturais do colonizador. Em alguns casos, o estranhamento deveria ser consideravelmente atenuado, principalmente pelo fato de que as etnias contatadas no litoral da América portuguesa tinham, em comum com os colonizadores lusos, uma predileção por frutos do mar, uma estratégica e saborosa fonte de proteínas e gordura. Os primeiros portugueses que observaram um grupo de tupinambás preparando um cascudo tamotatá (Hoplosternum littorale) devem ter salivado de fome e saudades de alguns pratos servidos na metrópole (Sousa, 1971, p. 296). A exemplo do modo lisboeta de se preparar sardinhas servidas na brasa, em alguma rua estreita do bairro de Alfama, os tupinambá também “[...] ao peixe não escamam nem lhe tiram as tripas, e assim como vem do mar ou dos rios, assim o cozem ou assam: o sal de que usam, com que temperam o seu comer, e em que molham o peixe [...]" (Sousa, 1971, p. 289).

Um peixe assado com escamas, vísceras e cabeça? Poucos pratos indígenas devem ter parecido tão familiares aos portugueses. Provavelmente, tal iguaria indígena deve ter se mostrado consideravelmente íntima aos moradores da colônia, em uma daquelas ocasiões em que o estranhamento culinário não ponderou os relatos sobre os hábitos alimentares do autóctone.

As receitas desenvolvidas e utilizadas nas cozinhas ibéricas demonstravam que o consumo de peixes inteiros, ou seja, com "tripas" e até mesmo com a cabeça, permaneceram, no século XVI, em várias receitas (Hue, 2008; Amorin, 1998). A partir do século XVII, em boa parte das descrições de pratos preparados com peixe, este passa a ser limpo por fora e por dentro, mantendo-se, em alguns casos apenas, 
a cabeça (Rodrigues, 2008). Nestas descrições da fauna ictiológica explorada na América portuguesa, notamos que as similitudes também poderiam se operar em nível gastronômico. A identidade alimentar, que o colonizador trazia da Europa, certamente o levava a uma busca por alimentos que pudessem não apenas supri-lo diariamente de fontes proteicas, mas também pudesse lhes remeter à sua terra de origem (Tuan, 1980, p. 106-128).

Podemos supor o quanto alguns frutos do mar, encontrados nas costas da América portuguesa, foram aceitos sem maiores problemas pelos colonizadores lusos. Afinal, estes eram tidos em alta conta na Europa quinhentista, pois estavam entre os alimentos dignos da nobreza (Cascudo, 1983; Abbade, 2009; Krondl, 2008, p. 121-135; Manupella; Arnaut, 1967). Havia, neste período, uma série de tratados e receitas advertindo quanto ao modo de preparo e consumo de peixes, assim como as mais variadas espécies de ostras. A popularidade dos alimentos extraídos do mar era tamanha que o gramático francês Gabriel Meurier chegou a cunhar um ditado que ficou popular no século XVI. Nele, Meurier afirmava que "O peixe que nasce na água deve morrer no óleo" (Loux, 1978, p. 286). Estes tratados culinários demonstravam, inclusive, quais eram as épocas do ano propícias para o consumo de peixes e frutos do mar, fossem eles mariscos, mexilhões ou ostras. Obviamente que tais informações mudavam de acordo com a região e, claro, podiam variar de cozinheiro para cozinheiro.

Com as ostras, por exemplo, era comum haver recomendações de precaução sobre seu consumo no verão, afinal, esta estação, por ser mais quente, não era propícia à conservação de tais moluscos ${ }^{4}$ (Flandrin; Montanari, 1998). O fato é que os europeus, neste caso, principalmente os Portugueses, estavam habituados a uma dieta rica em proteínas e gordura provenientes de animais marinhos (Abbade, 2009). Isto fica claro quando verificamos tratados culinários do século XVI como o de Meurier (1557), a qual estes alimentos podem ser

4 As recomendações feitas a respeito do consumo e preparo das ostras marinhas tinham absoluto fundamento, uma vez que estudos feitos atualmente revelam os riscos do consumo destes alimentos in natura (crus). Uma pesquisa feita com ostras da costa do Brasil revela que o "Vibrio parahaemolyticus é um agente patogênico humano que ocorre naturalmente nos ambientes marinhos. É frequentemente isolado a partir de peixes, polvos, camarões, caranguejos, lagostas, ostras e vieiras, sendo uma das principais espécies do gênero Vibrio que tem sido reconhecida como patógeno relevante distribuído nas regiões costeiras de clima temperado e tropical em todo o mundo" (Rodrigues; Carvalho-Filho, 2011). 
encontrados nas mais variadas receitas e, claro, nas próprias descrições dos colonizadores na América portuguesa.

O apreço ibérico por peixes fossem de água doce ou salgada, encontra-se disperso em receitas de obras como o Livro de cozinha da Infanta D. Maria, escrito no século XVI, e o Livro do Cozinheiro de Mestre Roberto de Nola, publicado em 1520 (Manupella; Arnaut, 1967; Nola, 2010). Tais obras citam o preparo e consumo de peixes em várias passagens. Ao menos, desde a Idade Média, pratos preparados com peixes frescos, defumados ou salgados faziam parte do cotidiano alimentar dos portugueses (Cascudo, 1983; Abbade, 2009; Krondl, 2008, P. 121-135; Manupella; Arnaut, 1967). Para os colonizadores lusos, adequar-se a uma dieta alimentar rica em peixes de água doce, ou frutos do mar, em alguns casos, exigiu pouco daquela propalada plasticidade. Afinal, peixes, moluscos e crustáceos já faziam parte do universo gastronômico português muito antes da construção das primeiras naus. Cidades banhadas por rios e mar, como Lisboa e Porto, ofereciam a seus moradores moluscos e peixes em relativa abundância, constituindo uma cultura alimentar baseada em alimentos extraídos da água ${ }^{5}$ (Cascudo, 1983; Manupella; Arnaut, 1967).

Durante processos colonizatórios, locais onde se encontravam consideráveis fontes de proteína e gordura animal, principalmente as de origem aquática, dificilmente eram ignorados ou desprezados (Kurlansky, 2009; Diamond, 2008; Saffron, 2004). Não é um padrão de expansão, mas regiões com oferta de água doce, proteína e gordura podem ser potencialmente atraentes ao colonizador.

Na América portuguesa devem ter sido observadas com apreço, pelos primeiros colonizadores, as espécies marinhas que mais se aproximavam daquelas já existentes em sua memória gustativa (Tuan, 1980). Gabriel Soares de Sousa destaca que as ostras encontradas nos

\footnotetext{
Manuppella e Arnaut, ao analisarem o livro de cozinha de Infanta D. Maria de Portugal, trabalham com registros que verificam a presença de peixes nos cardápios portugueses desde 1384. Há registros de navios que trafegavam no rio Tejo e que foram apreendidos com uma carga relativamente grande de peixes defumados e salgados, assim como lulas e polvos. No mesmo livro de cozinha, verificamos que, em 1269, havia um documento determinando que os comerciantes que estabelecem barracas para vender peixe frito no mercado de Coimbra, deveriam pagar um tributo por dia para ali se estabelecer (Manuppella; Arnaut, 1967). Tais relatos deixam claro que a presença de peixes e frutos do mar no cotidiano alimentar do europeu ibérico era fato, o que torna relevante observarmos os processos de adaptação alimentar dos colonizadores quinhentistas na América.
} 
trópicos eram, em grande parte, maiores e mais apetitosas que as do Reino (Sousa, 1971, p. 270). Este elogio, entretanto, não denota uma simples adaptação ao universo alimentar oferecido pela biota da colônia. Para aqueles colonizadores não se estava, simplesmente, apaziguando uma necessidade nutricional. As ostras encontradas na América portuguesa estavam proporcionando um prazer alimentar. O critério das analogias, neste caso, propiciou uma comparação onde o sabor das ostras da colônia eram, para Gabriel Soares, análogas às degustadas na metrópole.

A atenção dada às qualidades gustativas das ostras encontradas na América portuguesa demonstra que não devemos menosprezar o fato de que, mesmo em um ambiente relativamente inóspito, estes colonizadores não abandonaram simplesmente suas preferencias e hábitos alimentares. A questão não era somente a de se conseguir aplacar a fome, mas sim buscar, sempre que possível, o prazer em se alimentar de algo que pudesse remeter a cultura e história daqueles homens. A adaptação em novos ambientes nunca acontece enquanto mera transposição física. Processos de ocupação, por vezes, demostram que o colonizador busca, sempre que possível, construir ou encontrar características próximas as do local de sua origem (Fernández-Armesto, 2009). Isso pode ser verificado quando notamos a atenção dada, pelos cronistas, ao gosto dos alimentos advindos do mar. A busca por analogias gustativas, entre os sabores promovidos pelos frutos dos mares tropicais e aqueles encontrados nos mares da Europa, é recorrente entre os cronistas do século XVI. Esta apreciação, em alguns casos, poderia preceder ou mesmo substituir o estranhamento.

Estes colonizadores, sempre que podiam, se permitiam pequenos luxos culinários, mesmo que isso significasse navegar até alto mar para pescar, por exemplo, uma suculenta albacora:

[...] Se os senhores gulosos perdessem o medo ao mar e fossem aos trópicos apanhá-los, pois tal peixe não se aproxima das praias à distância suficiente para que possam os pescadores apanhá-los e traze-los sem que se corrompa, se os senhores gulosos os mandassem preparar com o molho da Alemanha ou de qualquer outro modo, certamente lamberiam os dedos [...] (Léry, 1961, p. 64).

Não é difícil entendermos porque aqueles homens se propunham a tais riscos, principalmente quando descobrimos que a albacora é uma espécie de atum. A preferência pelos peixes do gênero Thunnus atravessou séculos, e sua pesca sempre envolveu, no mínimo, o 
risco de navegar em alto mar (Hazin, 2010; Rebelo, 2010). Peixes migratórios que chegam a nadar até $170 \mathrm{~km}$ em um único dia, os atuns só podem ser capturados através de pesca oceânica. Um risco que, segundo Jean de Lery, os colonizadores da América portuguesa estavam, vez ou outra, dispostos a correr. O que não deveria ser simples no século XVI: navegar até mar aberto, com uma pequena embarcação.

Os perigos de tal pesca não se limitavam a mares revoltos, fortes correntes oceânicas ou perda de orientação em alto mar. O missionário francês lembra também que a distância navegada para se pescar albacoras se traduzia em tempo. O que poderia ser mais um agravante, afinal este "[...] peixe não se aproxima das praias à distância suficiente para que possam os pescadores apanhá-los e traze-los sem que se corrompa [...]" (Léry, 1961, p. 64, grifo nosso). Sem que se corrompa, ou seja, sem que esteja completamente podre. A questão logística da conservação das Albacoras pescadas reflete o problema da conservação da proteína, algo recorrente no século XVI. O perigo de bactérias saprófitas e outros organismos necrófagos se apoderarem do butim de pesca, em um ambiente claramente hostil e perigoso, como o alto mar, nos mostra até onde estes homens estavam dispostos a se arriscarem para saciarem, além da fome, um desejo.

A possibilidade de um prazer culinário em se comer alguns peixes da colônia não se restringiu às observações de um missionário francês. Adjetivos como "[...] muito avantajado no sabor e levidão [...]" (Sousa, 1971, p. 281) foram utilizados por um entusiasmado Gabriel Soares de Sousa que ressaltou o Guarapecu, mais pelo seu sabor do que forma:

[...] muito saboroso, e quando está gordo sabem as suas ventrechas a sável, cujo rabo é gordíssimo, e tem grandes ovas, em extremo saborosas; os seus ossos do focinho se desfazem todos entre os dentes em manteiga; e salpreso este peixe é muito gostoso, e se faz todo em folhas como pescada, mas é muito avantajado no sabor e levidão [...] (Sousa, 1971, p. 281).

Nas descrições de Léry e Gabriel Soares, o destaque é para o sabor. Para Jean de Léry, vale a pena correr o risco de se lançar ao mar para se saborear uma posta de albacora. Já Gabriel Soares não desperdiça nem mesmo as ovas, rabo e focinho do Guarapecu, um peixe hoje conhecido como cavala-wahoo (Acanthocybium solandri), vulgarmente nomeada de Cavala-empinge ou Aimpim (Szpilman, 2000, p. 241). As grandes ovas do Guarapecu poderiam não ser tão atrativas quanto a de um esturjão beluga (Huso huso), uma das espécies da qual se 
manufatura o caviar. Em todo caso, os 6 milhões de ovas geradas por uma fêmea de Acanthocybium deveriam render uma refeição considerável (Szpilman, 2000, p. 241).

Apesar de toda empolgação culinária que possamos identificar nas descrições da Albacora e do Guarapecu, Jean de Léry e Gabriel Soares de Sousa não nos deixam esquecer o delicado problema da manutenção de tais iguarias. Se, por um lado Lery coloca a questão da distância enquanto determinante para a conservação da Albacora, por outro, Gabriel Soares frisa que, mesmo depois de conservado em sal, o Guarapecu ainda "[...] é muito gostoso [...]" (Sousa, 1971, p. 281, grifo nosso). Uma indicação de que a técnica da salga podia até conservar o peixe, mas nem sempre aquilo que o tornava gostoso.

Quando Gabriel Soares e Jean de Léry afirmaram que um peixe podia ser muito gostoso ou de lamber os beiços, eles nos revelam desejos e preferencias ligados à alimentação. Além da busca diária por fontes de proteína e gordura animal, visando manter a sobrevivência, os colonizadores, sempre que podiam, se davam ao luxo de comer aquilo que, para eles, poderia ser considerado iguaria.

\section{Conclusões}

Obviamente, a importância dos alimentos pescados e coletados na costa, durante o processo de fixação e estabelecimento do europeu no Novo Mundo, não se limitou às estratégias de sobrevivência. Neste processo, também estava se consumindo, naquelas pescas e coletas, novos hábitos alimentares. Estes, oriundos de novos ingredientes e técnicas apresentadas, em grande parte, pelas etnias indígenas contatadas na faixa litorânea da América portuguesa. Os saberes indígenas foram inestimáveis, tanto à cultura culinária, quanto a própria sobrevivência dos primeiros colonizadores.

Quanto às reservas proteicas existentes na América portuguesa, principalmente aquelas capturadas, caçadas ou pescadas pelos colonizadores no ambiente da mata Atlântica, temos de nos lembrar de que, a despeito do senso comum, a diversidade faunística de florestas tropicais não se traduz em abundância (Odum, 2004, p. 57-64). Deste modo, fatores ambientais intrínsecos a uma floresta tropical, como a grande multiplicidade de espécies, por vezes, é interpretado de maneira equivocada, ou seja, como se a floresta fosse um grande depósito de proteína, gordura e carboidrato. A despeito deste sofisma ecológico, a realidade apresentada aos caçadores europeus do século XVI era a 
de que, dificilmente, manadas de antas ou cutias seriam facilmente encontradas. A ideia de abundância, tantas vezes associada ao ambiente da América portuguesa, pode se revelar um equívoco. Sobretudo quando o historiador desconhece fatores como diversidade neotropical, dinâmica de populações, etologia de crustáceos, ciclos migratórios, endemismos e balanço energético.

Ao que tudo indica, estes fatores ambientais pontuais estabeleceram um interessante diálogo com a cultura e técnicas relacionadas à alimentação dos primeiros europeus que desembarcaram, no século XVI, às bordas da mata atlântica. Enquanto o manejo do porco criado solto era repensado e a quantidade de punhados de sal a serem esfregados nos pernis e lombos reavaliados, a caça e pesca de animais nativos na colônia deve ter sido, aos olhos do colonizador, tão preciosa quanto às toras de pau-brasil ou pães de açúcar.

Paradoxalmente, parte da solução (e também do problema) passou a ser encontrar alimentos nativos da colônia, principalmente fontes de proteína e gordura animal, de forma eficiente e segura. Neste ponto, a fixação dos colonizadores no litoral pode ser considerada como estratégica à sobrevivência destes, afinal, os animais marinhos possuem alto teor de gordura e proteína, sendo que algumas espécies podem ser pescadas e ou coletadas com certa facilidade, possibilitando um baixo gasto calórico para tanto. Saber quais eram as condições ideias para se colher os frutos do mar, mostrou-se uma empreitada que exigiu, do colonizador, labor, tenacidade e um aguçado senso investigativo.

O século XVI, com as viagens ultramarinas e as novas colônias, revelou aos europeus através da visão, paladar e audição, uma ampliação daquilo que compreendiam sobre o mundo natural (Barreto, 1989). Neste período, o novo necessitava ser assimilado dentro do todo até então conhecido. Isto se deu, em boa medida, por meio das figuras de linguagem conhecidas como similitudes. $\mathrm{O}$ olhar atento do colonizador buscava naquilo que é novo, elementos que pudessem identificar marcas comuns a ambos os universos tentando, assim, encontrar aproximações entre aquilo que já se conhecia na Europa e o desconhecido no Novo Mundo (Assunção, 2001, p. 109-117).

Contudo, o apreço adquirido pelo gosto de albacoras e ostras não era regra nas descrições daquilo que o colonizador considerava comestível na colônia. Tampouco exceção. Cada um dos peixes, crustáceos e moluscos provados e descritos por viajantes e cronistas no século XVI, se encaixava em um critério ou demanda. Ao analisarmos tais descrições, podemos concluir que ao aportaram no Novo Mundo, os 
colonizadores ibéricos trouxeram uma ampla cultura culinária baseada em carne de suínos, peixes de água doce e frutos do mar. Mas isso não fazia com que eles estivessem dispostos a comer, de bom grado, qualquer bicho que saísse da água, ou que fosse criado em terra.

Deste processo de conhecimento e reconhecimento da natureza da América portuguesa, pelos homens que ali desembarcaram no século XVI, podemos verificar a construção de novos paradigmas no campo da Filosofia Natural do período. Uma perspectiva historiográfica multidisciplinar pode, portanto, nos ajudar a encontrar, nas crônicas e tratados do século XVI, um colonizador preocupado em conhecer e catalogar aqueles interessantes e (também) importantes animais da América portuguesa. Tal abordagem, ainda que parcialmente, permite, por fim, que observemos a busca por duas das necessidades mais básicas de um ser humano: conhecimento e comida.

\section{Referências}

ABBADE, Celina Márcia de Souza. Os textos da culinária Portuguesa revelando os costumes Medievais. Cadernos do Círculo Fluminense de Estudos Filológicos e Linguísticos, Rio de Janeiro: Cifefil, v. XII, n. 08, 2009.

AMORIN, Inês. Da pesca a salga da sardinha: recursos, tecnologia da pesca e tecnologia da conservação, na costa de Aveiro ( $2^{\mathrm{a}}$ metade do séc. XVIII a inícios de XIX). Porto: Universidade do Porto/Faculdade de Letras, 1998.

BERKEL, Brigitte Maas-van; BOOGAARD, Brigiet van den; HEIJNEN, Corlien. Conservação de peixe e carne. Wageningen: Fundação Agromisa, 2005.

CARDIM, Fernão. Tratados da terra e gente do Brasil. Belo Horizonte: Itatiaia, 1980. CASCUDO, Luis da Camara. História da alimentação no Brasil. São Paulo: Global, 2005.

CASE, Frances. 1001 comidas para provar antes de morrer. Prefácio de Gregg Wallace. Rio de Janeiro: Sextante, 2009.

CASTRO, Silvio. A carta de Pero Vaz de Caminha. Porto Alegre: L\&PM Editores, 1985. COSTA, Manuel Fernandes. O descobrimento da América e o Tratado de Tordesilhas. Lisboa: Instituto de Cultura Portuguesa, 1980.

COSTA, José P. C. da; BELO, Muracy; BARBOSA, José C. Efeitos de Espécies de Timbós (Derris spp.: Fabaceae) em populações de Musca domestica L. An. Soc. Entomol. Brasil, v. 26, n. 1, p. 163-168, 1997.

CROSBY, Alfred. Imperialismo ecológico: A expansão biológica da Europa 900-1900. São Paulo: Companhia das Letras, 1993.

DEAN, Warren. A ferro e fogo: a história e a devastação da mata atlântica brasileira. 2. ed. São Paulo: Companhia das Letras, 2010.

DELARIVA, Rosilene Luciana; AGOSTINHO, Angelo Antonio. Introdução de espécies: uma síntese comentada. Acta Scientiarum, v. 21, n. 2, p. 255-262, 1999. 
DIAMOND, Jared. Armas germes e aço: os destinos das sociedades humanas. Rio de Janeiro: Record, 2008.

FERRAZ DE ARRUDA, Lia; MARTINS, Priscila Eloi; SILVA, Adrana Figueiredo da; MORAES, Julieta E. Rodini de; VAZ-PIRES, Paulo; OZÓRIO, Rodrigo Otávio de Almeida; OETTERER, Marília. O Setor Pesqueiro em Portugal - Relato de caso. Bol. Inst. Pesca, v. 37, n. 2, p. 199-207, 2011.

FERNÁNDEZ-ARMESTO, Felipe. Os desbravadores: uma história mundial da exploração da Terra. Tradução Donaldson M. Garschagen. São Paulo: Companhia das Letras, 2009.

FERREIRA, Tiago Miguel de Lima. Produção de Suínos de raça Alentejana em sistema intensivo até ao final da pré-engorda. Dissertação (Mestrado em Produção Animal) - Universidade Técnica de Lisboa Faculdade de Medicina Veterinária, Lisboa, 2008.

FLANDRIN, Jean Louis; MONTANARI, Massimo. História da alimentação. 4. ed. São Paulo: Estação Liberdade, 1998.

GANDAVO, Pero de Magalhães. História da Província Santa Cruz. Rio de Janeiro: Obelisco, 1963.

GASPAR, Madu. Sambaqui: arqueologia do litoral brasileiro. Rio de Janeiro: Jorge Zahar, 2004.

HAZIN, Fábio Hissa Vieira. O futuro da pesca e da aquicultura marinha no brasil: a pesca oceânica. Ciência e Cultura, São Paulo, v. 62, n. 3, 2010. Disponível em: $<$ http://cienciaecultura.bvs.br/scielo.php?pid=S0009-7252010000300014\&script=sci_ arttext\&tlng=en>.

HOLZKAMM, Tim E.; WAISBERG, Leo G. Native American Utilization of Sturgeon. LEBRETON, Greg T. O.; BEAMISH, F. William H.; MCKINLEY, R. Scott (Ed.). Sturgeons and Paddlefish of North America. Dordrecht: Kluwer Academic Publishers. 2004, p. 22-36.

HUE, Moura Sheila. Delicias do descobrimento: a gastronomia brasileira no século XVI. Rio de Janeiro: Jorge Zahar, 2008.

KRONDL, Michael. Veneza, Lisboa e Amsterdã na rota das especiarias. Rio de Janeiro: Rocco, 2008.

KURLANSKY, Mark. A grande ostra: cultura, história e culinária de Nova York. Rio de Janeiro: José Olympio. 2009.

LÉRY, Jean de. Viagem à terra do Brasil. Rio de Janeiro: Biblioteca do Exercito, 1961.

LOUX; Richard. Sagesses du corps: la santé et la maladie dans les proverbes français. Paris: Maisonneuve et Larose, 1978.

LOPES, M.M. Culturas das Ciências Naturais/Cultures of Natural Sciences. Ciência \& Educação, v. 11, n. 3, p. 457-470, 2005.

MAGNOLI, Demétrio. Geografia: a construção do Mundo. São Paulo: Moderna, 2005.

MANUPPELLA, Giacinto; ARNAUT, Salvador Dias. O livro de cozinha da Infanta D. Maria de Portugal. Coimbra: Ordem da Universidade de Coimbra, 1967.

MARIANTE, Arthur da Silva, CAVALCANTE, Neusa. Animais do descobrimento: raças domésticas da história do Brasil/Animals of the discovery: domestic breeds in the history of Brasil. 2. ed. Brasília, DF: Embrapa Informação Tecnológica, 2006. 
ODUM, Eugene P. Fundamentos de Ecologia. Lisboa: Fundação Calouste Gulbenkian, 2004.

QUAMMEN, David. O canto do dodô: biogeografia de ilhas numa era de extinções. São Paulo: Companhia das Letras, 2008.

REBELO, Maria José Fortes. As indústrias da pesca e conservas de atum no Algarve do Século XX. [Tese - Universidade de Algarve], Algarve: Editora MJFR, 2010.

REITZ, Elizabeth J. The Spanish Colonial Experience and Domestic Animals. Historical Archaeology, v. 26, n. 1, The Archaeology of the Spanish Colonial and Mexican Republican Periods, p. 84-91, 1992.

RODRIGUES, Domingos. 1637-1719: Arte de Cozinha, 1680. Rio de Janeiro: SENAC Rio de Janeiro, 2008.

RODRIGUES, Leticia de Alencar Pereira; CARVALHO FILHO, Celso Duarte. Ocorrência de Vibrio parahaemolitycus nas etapas de beneficiamento de ostras (Crassostrea rhizophorae), Cultivadas na Baía de Todos os Santos-BA, e Determinação dos Pontos Críticos de Controle. UNOPAR Cient. Ciênc. Biol. Saúde, v. 13, p. 77-83, 2011.

SAFFRON, Inga. Caviar: a estranha história e o futuro incerto da iguaria mais cobiçada do mundo. Rio de Janeiro: Intrínseca, 2004.

SANTOS, C. F. M.; FERREIRA, Vítor de Souza; CARREIRA, Lígia. A América e o morcego hematófago no relato de viajantes quinhentistas. Varia História, Belo Horizonte, v. 23, p. 561-573, 2007.

SANTOS, Christian F. M. dos; MOTTA, Lúcio Tadeu; GONÇALVES, José Henrique Rollo. Estratégia e adaptabilidade alimentares na América portuguesa do século XVIII: alguns casos Monçoeiros. Diálogos, DHI/PPH/UEM, v. 14, n. 2, p. 273-286, 2010.

SOUSA, Gabriel Soares de. Tratado Descritivo do Brasil. São Paulo: Brasiliana, 1971.

SOUZA, Rosa Cristina Corrêa Luz de; LIMA, Tania Andrade, SILVA, Edson Pereira da. Conchas marinhas de Sambaquis do Brasil. 1. ed. Rio de Janeiro: Technical Books, 2011.

SZPILMAN, Marcelo. Peixes marinhos no Brasil: guia prático de identificação. Rio de Janeiro: Mauad, 2000.

THÉVET, André. As singularidades da França Antártica. Belo Horizonte/São Paulo: Itatiaia/Editora da Universidade de São Paulo, 1978.

TUAN, Yi-Fu. "Topofilía”: um estudo da percepção, atitudes e valores do meio ambiente. São Paulo/Rio de Janeiro: Difel, 1980. 